\title{
An Econometric Study of the Demand for Fertilizers in Pakistan
}

\section{MAHMOOD A. AYUB*}

An empirical study of the demand for fertilizers in Pakistan is important for at least two reasons. First, we can identify the various factors responsible for the determination of demand. This will obviously depend to a large extent on the arguments we include in the demand function and the mathematical specification of the model. Nevertheless, one can obtain a rough idea of the importance of the various factors in the total demand for fertilizers. Second, a study of the demand side will enable us to obtain some estimates of the price elasticity of demand. Knowledge of price elasticity is extremely essential from the government policy point of view because the sale of fertilizers in Pakistan has been subsidized, and it is, therefore, essential to know the degree of responsiveness of fertilizer demand to price changes.

Despite the crucial importance for policy measures, hardly any econometric study of the demand for fertilizers has been carried out in Pakistan. To the best of my knowledge, P.L. Leonard [5] is the only one who has attempted to carry out such a study for Pakistan. The aim of this paper is, therefore, to quantify the degree of importance of the various factors in the fertilizer demand of Pakistan.

This paper is divided into 2 main parts. In the first part, we examine Leonard's study carefully both from the theoretical point of view and its policy implications. Specifically, we ask: To what extent are the policy implications of Leonard's study the result of some elementary pitfalls in his econometric study? In the second part, we offer an alternative procedure of estimation which we believe is superior to Leonard's, both theoretically and in its main

The author, a Ph.D. student in Economics at Yale University, would like to thank several individuals for assistance in the collection of the data. He is indebted to Mr. Mohammed Ayub, Mr. John T. Shields, Agricultural Economist, International Fertilizer Dovelopment Staff of Tennessee Valley Authority, Mr. John Hill of A.I.D./Washington, Mr. James Unti, Agricultural Economie Advisor, U.S.A.I.D., Islamabad, and Dr. Haider Ali Chaudhari, Dean, University of Agriculture, Lyallpur, Pakistan. Finally, he acknowledges the helpful comments, on an earlier draft of this paper, by the referees to this Journal and by Professors Robert Evenson and Kim Peck. 
results. We also test a hypothesis about the constancy or otherwise of the coefficient of price elasticity over time. It will be shown that it is naive to assume a constant value of the coefficient for the whole period.

Leonard's model includes a time series analysis for the period 1952 to 1968 for (formerly West) Pakistan. He fits a number of functions to the data, using the total consumption of fertilizers as the dependent variable. The independent variables he uses include

$X_{1}$ - a time variable for measuring levels of technology and information, $X_{1}$ - deflated price of fertilizer at farm level (deflated by agricultural income index, $\mathrm{X}_{5}$ ),

$X_{1}$ - the total acreage of cultivated land in the previous twelve months,

$\mathbf{X}_{\text {. }}$ - the average size of holding cultivated,

$\mathbf{X}_{\mathbf{6}}=$ index of agricultural income, based on average net income for four major crops in (West) Pakistan-wheat, rice, sugar-cane and cotton,

$X_{0}=$ sales of fertilizer in the previous year,

$X_{7}=$ irrigation index the percentage of the cultivated land which is irrigated.

Leonard's study consists of two parts. In the first section, he fits time series data to functions which are linear, log-linear, adjustment-type and first differences in logs. The results are shown below. Throughout the paper, the figures in the parentheses refer to standard errors of the coefficients.

Leonard's Results from Time-Series Analysis

\begin{tabular}{cccccc}
\hline Form of Equation & Constant & $\begin{array}{c}\text { Time } \\
\mathbf{X}_{1}\end{array}$ & $\begin{array}{c}\text { Deflated } \\
\text { Price } \\
\mathbf{X}_{\mathbf{1}}\end{array}$ & $\begin{array}{c}\text { Lagged } \\
\text { Sales of } \\
\text { Fertilizer }\end{array}$ & $\overline{\mathbf{R}}^{\mathbf{2}}$ \\
& & & & $\mathrm{X}_{\mathbf{6}}$ & \\
& & & &
\end{tabular}

1. Linear

2. Log Linear

3. Adjustment Model

0.6421

4. First Differences in Logs
-

$-38.41$

1.21

2.19

$\begin{array}{lr}49.95 & -32.92 \\ (3.72) & (28.1)\end{array}$

0.11

$(0.02)$

$-0.13$

(0.11)

$-0.04$

$(0.21)$

0.74

$(0.10)$

0.70

0.98

0.81

(0.10)

$-1.08$

(0.5)

The conclusion he arrives at, on the basis of the above results, is that price is not a significant determinant of demands.

To confirm this result, Leonard next uses cross-sectional data on district demand. The model was tested for data for three years from 32 districts. the following results were obtained. 
Leonard's Results from Cross-Sectional Analysis

\begin{tabular}{|c|c|c|}
\hline & Form of & Equation \\
\hline & Linear & Log Linear \\
\hline Constant & -83.05 & -7.29 \\
\hline Time $X_{1}$ & - & $\begin{array}{c}+0.41 \\
(0.08)\end{array}$ \\
\hline Price $\mathrm{X}_{2}$ & - & $\begin{array}{r}0.09 \\
(0.10)\end{array}$ \\
\hline Acreage $\mathbf{X}_{3}$ & $\begin{array}{r}6.15 \\
(1.66)\end{array}$ & - \\
\hline Size of Holding $X_{4}$ & $\begin{array}{r}183.19 \\
(294.75)\end{array}$ & - \\
\hline Index of Agricultural Income $X_{5}$ & $\begin{array}{r}50.45 \\
(46.50)\end{array}$ & $\begin{array}{r}2.65 \\
(0.39)\end{array}$ \\
\hline Lagged Sales of Fertilizer $X_{6}$ & $\begin{array}{r}0.38 \\
(0.002)\end{array}$ & $\begin{array}{r}-0.24 \\
(0.13)\end{array}$ \\
\hline Irrigation Index $\mathbf{X}_{\mathbf{7}}$ & $\begin{array}{r}24.94 \\
(31.51)\end{array}$ & - \\
\hline$\overline{\mathbf{R}}^{2}$ & 0.58 & 0.44 \\
\hline
\end{tabular}


On the basis of his study, Leonard concluded that income, but not price, is a significant determinant of the level of demand for fertilizers. He suggests that the removal of the subsidy on fertilizers would have almost no long run effect, since the subsidy constitutes an economic rent.

Since Leonard's conclusion is so crucial for agricultural policy with respect to fertilizers, it is important to examine his model in detail. A careful study of his theoretical model and interpretation of results indicates a number of flaws in his analysis, and we hypothesize that his conclusion may perhaps be influenced by these flaws.

The first flaw of Leonard's analysis is that his measure of price elasticity from first differences is wrong (page 421). The coefficient of price in first differences is not a measure of price elasticity. Moreover, when one is performing a.regression analysis in first differences, the constant term should not be inserted. It is trivial to show that if our original regression equation is

$$
\mathrm{Y}_{\mathrm{t}}=\alpha+\beta \mathrm{X}_{\mathrm{t}}+u_{\mathrm{t}} \ldots \ldots \ldots \ldots \ldots \ldots \ldots
$$

then, lagging (i) by one period,

$$
Y_{n-1}=\alpha+\beta X_{b-1}+u_{b-1}
$$

and subtracting (ii) from (i) we get

$$
\left(Y_{t}-Y_{L-1}\right)=B\left(X_{1}-X_{t-1}\right)+\left(u_{t}-u_{-1}\right)
$$

which is devoid of a constant (intercept) term.

A somewhat more serious error is the application of ordinary least squares to a regression with lagged dependent variables. Leonard's lagged adjustment model has the sales of fertilizers lagged one year $\left(X_{0}\right)$ as one of the variables on the right hand side. As Johnston [4] points out, lagged dependent variables with random disturbances will give ordinary least squares estimators which are consistent, though biased in finite samples. Also autocorrelated disturbances without lagged dependent values do not produce biased estimators, even in small samples; but the combination of the two problems gives estimates which are not only biased but also inconsistent. In Leonard's model, the use of lagged dependent value of sales does not of itself invalidate the use of ordinary least squares; but in a time series study such as Leonard's, there is almost invariably significant positive autocorrelation. One is, therefore, forced to use other estimation methods, such as Dhrymes's [1] method or Wallis's Three Pass Least squares method [6]. Recently Hatanaka [3] has developed a new technique which gives estimates which are not only consistent but also efficient.

The final error in Leonard's analysis is that he compares the values of $\overline{\mathbf{R}}^{\mathbf{2}}$ from linear and log-linear forms (page 424, line 4). As Goldberger [2] has noted when the regressand has been transformed, the $\bar{R}^{2}$ value may be misleading as a measure of goodness of fit. Thus if a double log form has been fit (as has been done by Leonard) the $\overline{\mathbf{R}}^{\mathbf{2}}$ measures the proportion of the variation of the logarithm of the regressand that has been accounted for, which is different from the proportion of variation of the regressand. In all such cases where one is comparing correlation coefficients from different functional forms, the correct procedure is to convert all computed values of the dependent variable, for all the different functional forms, into absolute values and then compute new correlation coefficients on the basis of these absolute values. 
The above, then, are some of the drawbacks of Leonard's analysis.

\section{II}

The first step is to replace the use of ordinary least squares by an estimation procedure which takes cognizance of autocorrelation coupled with a lagged endogenous (consumption of fertilizers) term. We opt for Wallis's three pass least squares method of estimation, although, in principle, one has a choice of several techniques. Using Wallis's method, the estimation was carried out in both linear and log-linear forms, and the results are given below equations 1 and 2 , respectively,
1. $\mathrm{Y}=947.58+$
$2.65 \mathrm{X}_{2}-$
$(2.83)$
$73.74 X_{2}$
$(23.01)$
$\underset{(27.82)}{95.21 X_{k}}+$
$0.70 \mathrm{X}_{6}$
$(0.21)$

$$
R^{2}=0.986 \text {, D.W. }=2.57
$$
2. $\log Y=3.85+0.31 \log X_{2}-2.01 \log X_{3}+2.39 \log X_{b}$
$\begin{array}{lll}(3.07) \quad(0.13) & (1.22) & (0.52)\end{array}$
$+0.33 \log \mathrm{X}_{\mathrm{a}}$
$(0.13)$

$R^{2}=0.994, \quad$ D.W. $=1.98$

The results are not very helpful, and one suspects that the use of a more sophisticated technique of estimation does little to improve the fit. The coefficients of income and lagged consumption both have the right sign and are significant, but the signs on the price and lagged acreage coefficients are wrong. What is more, the use of two stage least squares (using subsidy as an instrumental variable for price) did not result in any better results. We are, therefore, convinced that the problem does not lie in the application of better estimation techniques.

From the theoretical point of view, there is reason to believe that the values of certain parameters change over time. In particular, it would be reasonable to expect that, instead of the price coefficient having a single value for the whole period under review, it has changed significantly. In the early part of the period, price was not a significant factor in the determination of the demand for fertilizers. However, over the years, and particularly after the advent of the high-yielding varieties of seeds, farmers have become more sensitive to changes in the price of fertilizers. One way of testing the hypothesis. that the price elasticity of demand for fertilizers has changed is to split the whole period (1958-1973) into 2 parts. While this division is somewhat arbitrary, we found that the results are not affected by where we draw the dividing line. For simplicity we divided the period into two equal parts $1958-1965$ and 1966-1973.

The hypothesis is upheld strikingly by the results shown in the tables 


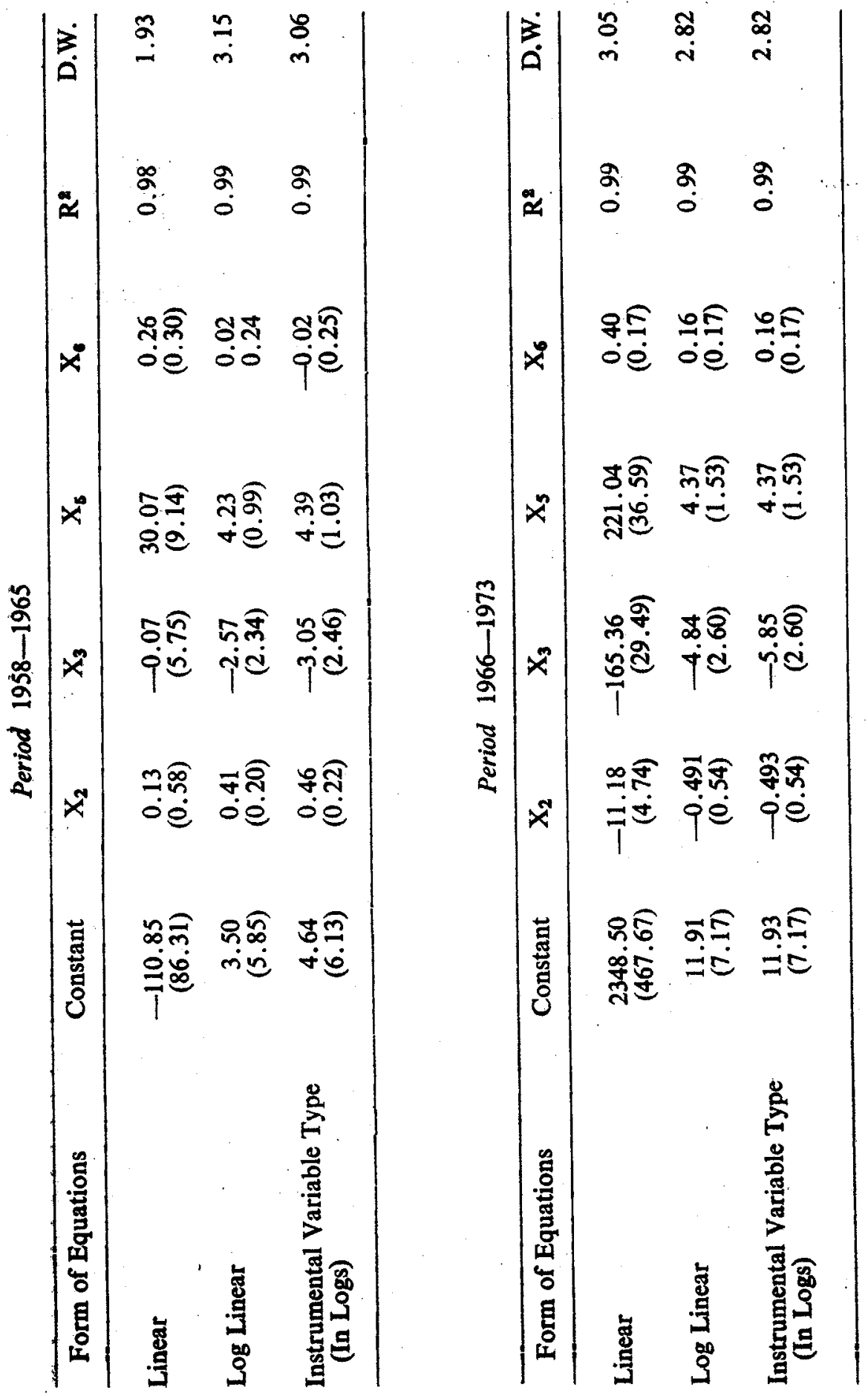


Since our principal concern is to test the hypothesis about the price coefficient, we shall not dwell on the results for the other coefficients. The tables indicate that, regardless of the different specifications, the price coefficient for the first period is insignificant (and has the wrong sign). On the other hand, the price coefficient for the second period has the right sign in the log linear and instrumental variable case, whereas in the linear case, it is not only of the right sign but is also significant at $10 \%$ level of significance. From the table for the second period, the price elasticity of demand for fertilizers (given as the price coefficient in the logarithmic form) is -0.491 . The value obtained by the use of two stage least squares is -0.493 , thus confirming our result. This value is almost four times as high as Leonard's figure of -0.13 for the period 19521968.

The implication of the above analysis is that in examining the role of fertilizer prices in the determination of demand for fertilizers, it makes more sense to split up the whole period into two parts (or even more than two, except that we will run short of degrees of freedom) and measure the price coefficients separately. Our analysis reveals that whereas in the first period (1958-1965), price was an insignificant factor, it was more important in the second period (1966-1973). We, therefore, disagree with Leonard's conclusion that the price subsidy should be removed.

\section{References}

1. Dhrymes, P. Econometrics. New York: Harper and Row. 1970.

2. Goldberger, A. Econometric Theory. New York: John Wiley. 1964.

3. Hatanaka, M. "An Efficient Two-Step Estimator for the Dynamic Adjustment Model with Autoregressive Errors." Econometrica (forthcoming).

4. Johnston, J. Econometric Methods. (Second Edition.) New York: McGraw-Hill Book Company. 1972.

5. Leonard, P. "The Demand for Fertilizers in Pakistan." Pakistan Development Review. Vol. IX, No. 4. Winter 1969.

6. Wallis, F. K. "Lagged Dependent Variables and Serially Correlated Errors: A Reappraisal of Three-Pass Least-Squares." Review of Economics and Statistics. Vol. 49. 1967. 